\title{
UTILIZAÇÃO DE FILME STRECH EM PARÂMETROS FÍSICO-QUÍMICOS E MICROBIOLÓGICOS DE CARCAÇAS BOVINAS
}

\author{
WILLIAN FONSECA DE FREITAS * \\ ANA MARIA CENTOLA VIDAL MARTINS* \\ GABRIEL AUGUSTO MARQUES ROSSI* \\ JÚLIO CESAR DE CARVALHO BALIEIRO** \\ CARLOS EDUARDO GAMERO AGUILAR*** \\ FABIO ADRIANO FRANCO BENITES* \\ NATÁSSIA PRADO ROSA*
}

\begin{abstract}
Objetivou-se avaliar o efeito da utilização do filme strech sobre parâmetros físico-químicos e microbiológicos de carcaças bovinas. Foi avaliado um total de 25 carcaças, sendo 25 meias carcaças strechadas e 25 não strechadas, obtidas do mesmo animal, após a lavagem final e após o período de 24 horas da maturação sanitária na câmara fria. As meias carcaças foram submetidas à aferição do $\mathrm{pH}$ e da temperatura no interior do Longissimus dorsi e a pesagem. Também foram coletados suabes para a contagempadrão em placas de microrganismos mesófilos e psicrotróficos viáveis e a verificação da presença de enterobactérias e Listeria spp. Após a maturação sanitária, as carcaças strechadas apresentaram temperaturas mais elevadas $\left(1,86^{\circ} \mathrm{C}\right)$ em relação as não strechadas $\left(0,57^{\circ} \mathrm{C}\right)$, com diferença estatística $(p<0,05)$, o que favoreceu o crescimento de microrganismos mesófilos, os quais também diferiram significativamente $(p<0,05)$. Esse indicador microbiológico foi analisado com base no seu logaritmo, que foi de 2,62 UFC/cm² para as carcaças não strechadas e 3,49 UFC/ $\mathrm{cm}^{2}$ nas carcaças strechadas, após a maturação sanitária. Não foi observada diferença significativa nos demais parâmetros avaliados. Conclui-se que a utilização do filme strech faz com que as carcaças permaneçam com temperaturas mais elevadas após a maturação sanitária e, assim, favorece a multiplicação de microrganismos mesófilos.
\end{abstract}

PALAVRAS-CHAVE: ENTEROBACTÉRIAS; LISTERIA SPP.; MATURAÇÃO SANITÁRIA; MESÓFILOS; PSICROTRÓFICOS.

*Médico veterinário autônomo (e-mails: willian.freitas@usp.br, fabiobenitesvet@gmail.com, natassia@hotmail. com).

** Departamento de Medicina Veterinária, Faculdade de Zootecnia e Engenharia de Alimentos (FZEA), Universidade de São Paulo (USP), av. Duque de Caxias Norte, 225, Pirassununga, SP, CEP 13635-900, Brasil (e-mails: anamartins@usp.br, balieiro@usp.br).

*** Faculdade de Ciências Agrárias e Veterinárias, Universidade Estadual Paulista (UNESP), via de acesso Prof. Paulo Donatto Castellane, s/n, CEP 14884-900, Jaboticabal, SP (e-mails: gabrielrossiveterinario@ gmail.com, kadugamero@hotmail.com). 


\section{INTRODUÇÃO}

A cadeia produtiva da carne bovina brasileira vem se destacando ao longo dos anos e conquistando posições importantes no cenário mundial. Somente no ano de 2013 , realizou-se o abate de 26.204.002 bovinos (BRASIL, 2014) e foram exportadas 1.183.246 toneladas de carne in natura (ABIEC, 2014). Sendo assim, com uma alta produção e comercialização, tornase evidente a preocupação com a segurança e a qualidade desses produtos, visando atender às necessidades dos consumidores através do fornecimento de alimentos inócuos à saúde.

Segundo Pardi et al. (2001), o processo de refrigeração é um dos procedimentos para controlar a multiplicação dos microrganismos responsáveis pela deterioração dos produtos e contribui para o controle das infecções e toxinfecções alimentares, em virtude da incapacidade da maioria de seus agentes de se multiplicar em temperaturas situadas em torno dos $4{ }^{\circ} \mathrm{C}$. Entretanto, quando utilizado frio extremo, pode provocar queimaduras na carne, com consequentes alterações sensoriais (EVANGELISTA, 2000).

No Brasil, a legislação preconiza que, após o abate dos animais, as carcaças bovinas são mantidas em câmaras frias, onde permanecem por volta de 24 horas. As temperaturas decrescem até próximo de $0{ }^{\circ} \mathrm{C}$, não devendo ultrapassar os $7{ }^{\circ} \mathrm{C}$ no interior do músculo Longissimus dorsi quando de sua saída desse local (BRASIL, 1997).

Nesse período, há o estabelecimento do rigor mortis, em que ocorrem transformações enzimáticas e bioquímicas, caracterizando a chamada conversão do músculo em carne, através da glicólise anaeróbica. Essa via metabólica faz com que ocorra o acúmulo de ácido láctico no músculo e, consequentemente, o $\mathrm{pH}$ da carne decresce gradativamente de próximo da neutralidade até valores de aproximadamente 5,3 a 5,8, o que seria outro fator controlador do crescimento bacteriano (SAVELL, MUELLER e BAIRD, 2005). Essa alteração do pH influencia diretamente ainda a quantidade de água retida na carne, pois ocorre exsudação de líquido com consequente perda de peso (HUFF-LONERGAN e LONERGAN, 2005), correspondente a entre $1 \%$ e $2 \%$ do peso da carcaça quente (JAMES, 1996).

Para avaliar a qualidade microbiológica dessas carcaças bovinas, podem ser utilizados alguns grupos de microrganismos indicadores, como os mesófilos, que não necessariamente indicam a presença de patogênicos, mas que estão relacionados com a higiene durante as etapas de produção dos alimentos e com a manutenção deles em temperaturas adequadas (ICMSF, 1984). Lopes e Oliveira (2002) demonstraram que houve redução de cerca de um ciclo logarítmico nas contagens de mesófilos em carcaças após a entrada nas câmaras frias.

Phillips et al. (2001) analisaram carcaças bovinas após refrigeração e encontraram

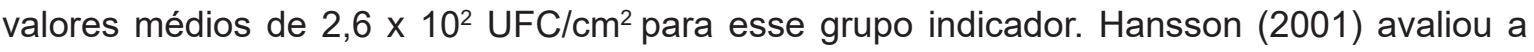
contagem desse grupo em plantas frigoríficas com alta e baixa capacidade de abate, encontrando valores médios de $3,8 \times 10^{2} \mathrm{UFC} / \mathrm{cm}^{2}$ e $2,7 \times 10^{3} \mathrm{UFC} / \mathrm{cm}^{2}$ respectivamente.

Outro grupo indicador da conservação do produto, relacionado com a deterioração da carne produzida, é o dos microrganismos psicrotróficos, que, após adaptação ao novo ambiente, iniciam uma fase de multiplicação que resulta no aparecimento de maus odores ou limo (GARCIA-LÓPEZ, PRIETO e OTERO, 1998).

Porém, alguns grupos de microrganismos, como os das enterobactérias, apresentam riscos diretos de agravos à saúde dos consumidores (ICMSF,1984). Também com importância em segurança alimentar e saúde pública, destaca-se a Listeria monocytogenes, que possui capacidade de rápida multiplicação mesmo em temperatura de refrigeração. Matos et al. (2013) avaliaram 300 carcaças bovinas e não observaram a presença de Listeria monocytogenes em nenhuma amostra. Entretanto, Silveira (2010) encontrou 12 carcaças de 110 bovinos contaminadas com Listeria spp., sendo encontrada com maior frequência nas etapas iniciais do processo de abate. 
A fim de minimizar os efeitos negativos, como a perda de peso das carcaças e a queima das superfícies destas com consequente retirada das regiões afetadas durante a desossa, ambas causadas pelas baixas temperaturas durante o período de refrigeração, alguns frigoríficos estão adotando o uso de um filme de polietileno que reveste a carcaça ("filme strech") durante as 24 horas em que ela permanece na câmara fria (período de maturação sanitária), o qual posteriormente é removido para que a desossa seja realizada. Diante de tal fato, o presente trabalho objetivou avaliar o efeito da utilização do filme strech em parâmetros físico-químicos e microbiológicos de carcaças bovinas.

\section{MATERIAIS E MÉTODOS}

O frigorífico em que o trabalho foi realizado situa-se no estado de São Paulo e é submetido a um controle higiênico-sanitário permanente através do Serviço de Inspeção Federal (SIF).

Foi avaliado um total de 25 carcaças, sendo o tratamento 1 composto por 25 meias carcaças strechadas (S), e o tratamento 2, por 25 não strechadas (NS), obtidas do mesmo animal. No frigorífico, as meias carcaças também foram submetidas à aferição do $\mathrm{pH}$ e da temperatura no interior do músculo Longissimus dorsi (entre a $12^{\mathrm{a}}$ e a $13^{\mathrm{a}}$ costelas) e a pesagem na balança do frigorífico.

Estas foram amostradas logo após a lavagem final (T0) e após o período de maturação sanitária de 24 horas na câmara fria (T24), totalizando cem amostras. A coleta de amostras foi realizada em três pontos das carcaças através de suabes aplicados na região do coxão, lombo e ponta de agulha em áreas de $20 \mathrm{~cm}^{2}$ em cada ponto, utilizando-se um gabarito em aço inoxidável estéril (APHA, 2001). Os suabes foram armazenados em meio de transporte para posterior verificação do perfil microbiológico de cada meia carcaça no Laboratório Multiusuário de Saúde Animal e Segurança Alimentar da FZEA/USP.

Para avaliação do perfil microbiológico foi realizada a contagem-padrão em placas de microrganismos mesófilos e psicrotróficos viáveis (APHA, 2001). Primeiramente, foram preparadas diluições decimais da solução de transporte dos suabes, sendo a inicial $\left(10^{-1}\right)$ obtida a partir da mistura de $1 \mathrm{ml}$ da referida solução com $9 \mathrm{ml}$ de água peptonada a $0,1 \%$. Diluições sucessivas até $10^{-2}$ foram preparadas, semeadas em ágar-padrão para a contagem e uma série de placas foi incubada a $37^{\circ} \mathrm{C}$ por 48 horas para a contagem de mesófilos e outras a $7^{\circ} \mathrm{C}$ por dez dias para a contagem de psicrotróficos. As contagens foram realizadas em contador de colônias, segundo a técnica-padrão.

Também foi determinada a presença ou ausência de enterobactérias utilizando-se 1 $\mathrm{ml}$ de cada diluição, que foi semeada em profundidade em ágar glicose vermelho-violeta bile (VRBGA) e incubada em microaerofilia a $37^{\circ} \mathrm{C} / 48 \mathrm{~h}$ (VIEIRA et al., 2009).

Ainda, as amostras foram avaliadas para a presença de Listeria spp. de acordo com a metodologia preconizada pelo United States Departament of Agriculture. Para o enriquecimento seletivo primário foi utilizado o caldo-base seletivo Listeria, incubado a $30^{\circ} \mathrm{C} / 24 \mathrm{~h}$, seguido do secundário em caldo Fraser, incubado a $35{ }^{\circ} \mathrm{C} / 24 \mathrm{~h}-40 \mathrm{~h}$. Após a fase de enriquecimento, o plaqueamento seletivo diferencial foi feito em Oxford Medium Base, com incubação de $35{ }^{\circ} \mathrm{C}$ por 24h/48h (USDA, 1996).

A análise estatística dos dados foi realizada utilizando o método do qui-quadrado ou teste $t$ de Student a $5 \%$ de significância.

Número do protocolo de aprovação em comitê de ética (CEP/FZEA): 2014.1.76.74.6.

\section{RESULTADOS E DISCUSSÃO}


Em relação ao $\mathrm{pH}$, observou-se a queda clássica decorrente da transformação do músculo em carne, que ocorre durante a maturação sanitária, em que houve apenas a influência do tempo (T0 x T24), sendo que a utilização do filme strech (T1 x T2) não interferiu nos resultados. $\mathrm{O}$ pH observado em carcaças strechadas durante o T0 foi, em média, de 6,42, e no T24 foi de 5,80, enquanto, para as carcaças sem a utilização do filme, o pH durante T0 e T24 foi, em média, 6,58 e 5,84 respectivamente. Esses dados concordam com o trabalho realizado por Sampaio (2013), em que não se observou diferença estatística em relação ao pH entre carcaças revestidas com tal filme em relação àquelas em que não foi utilizado.

O peso das carcaças após 24 horas (T24) não diferiu estatisticamente entre os tratamentos, sendo, em média, de 159,46 kg nas carcaças não strechadas e de 163,88 kg nas strechadas. Portanto, não houve diferença em relação à perda de peso entre os tratamentos e esse dado diferiu do resultado verificado por Sampaio (2013), que encontrou redução significativa $(p<0,05)$ em todas as perdas de peso das meias carcaças com o uso do revestimento plástico durante as primeiras 24 horas de resfriamento. Porém, observou-se maior média de peso nas carcaças que receberam tratamento com filme strech em relação àquelas que não receberam tal tratamento, com diferença de 4,42 kg (2,70\%).

Com relação à aferição da temperatura, foi observado que houve diferença $(p<0,05)$ entre os tratamentos após 24 horas de refrigeração. As carcaças strechadas (T1), em média, apresentaram temperaturas mais elevadas $\left(1,86{ }^{\circ} \mathrm{C}\right)$ em relação às não strechadas $(\mathrm{T} 2)$ $\left(0,57^{\circ} \mathrm{C}\right)$. Tal fato favoreceu o crescimento de microrganismos mesófilos, os quais diferiram significativamente $(p<0,05)$, conforme pode ser observado na figura 1.

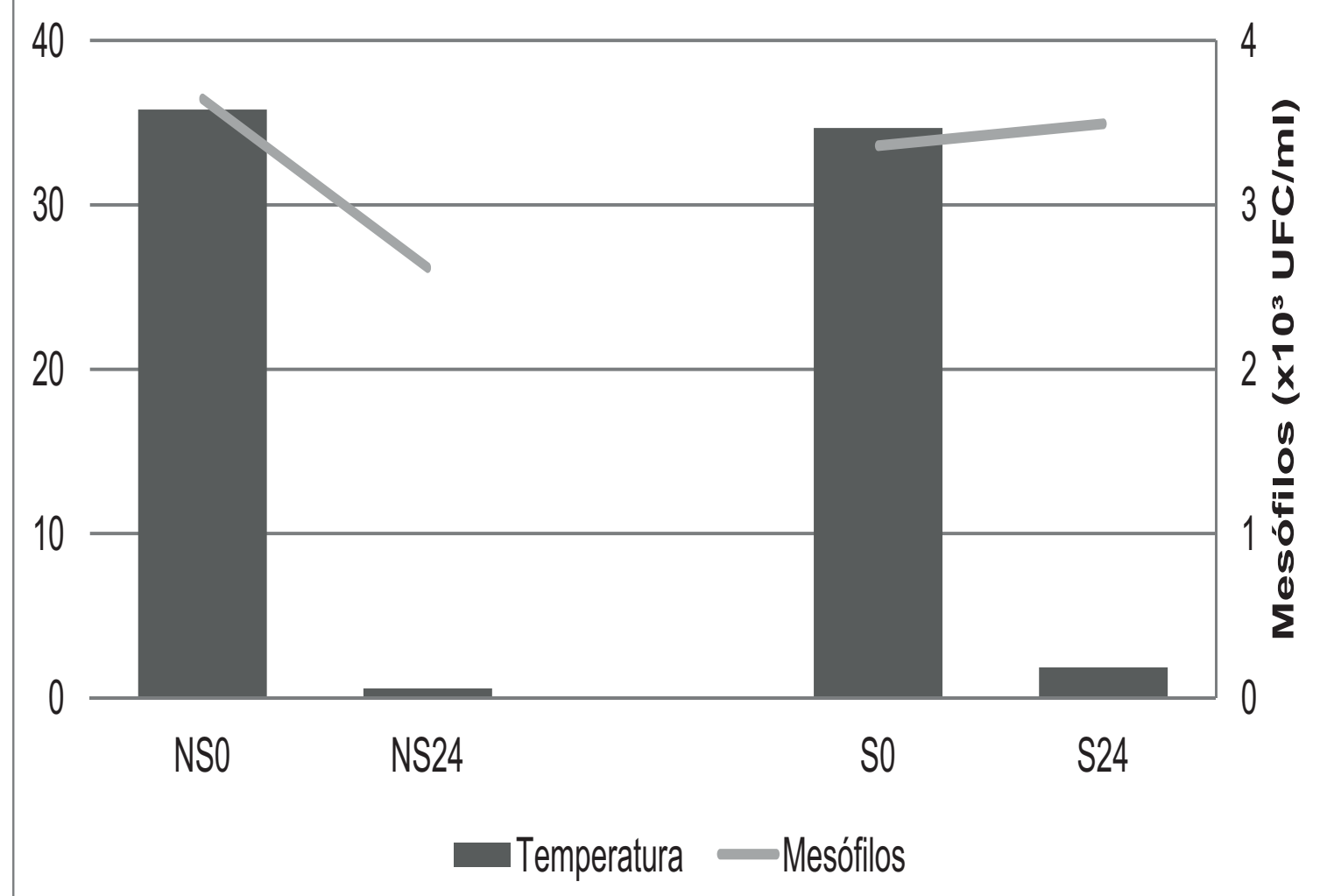

FIGURA 1 - QUEDA DA TEMPERATURA $\left({ }^{\circ} \mathrm{C}\right)$ E CONTAGEM DE MICRORGANISMOS MESÓFILOS (UFC/ML) EM CARCAÇAS BOVINAS COM E SEM ENVELOPAMENTO ATRAVÉS DA UTILIZAÇÃO DO FILME STRECH DURANTE AS 24 HORAS DE MATURAÇÃO NA CÂMARA FRIA 
Os microrganismos mesófilos foram analisados com base no seu logaritmo, que foi de 2,62 UFC/ $\mathrm{cm}^{2}$ para as carcaças não strechadas e $3,49 \mathrm{UFC} / \mathrm{cm}^{2}$ nas carcaças strechadas, ambas após 24 horas de maturação sanitária. Esses dados são semelhantes aos resultados encontrados por Sampaio (2013), demonstrando que o filme strech provavelmente funcione como um isolante térmico, dificultando assim a troca de calor entre a superfície da meia carcaça e o ambiente da câmara e favorecendo o crescimento de microrganismos mesófilos.

A quantificação de microrganismos mesófilos está relacionada com as etapas de limpeza e desinfecção, além da manutenção dos produtos em temperaturas adequadas durante a produção e o armazenamento, sendo utilizados para determinar a vida útil dos alimentos (ICMSF, 1984). Ainda, apresenta relação com a ocorrência de microrganismos patogênicos como enterobactérias, Bacillus sp., Clostridium sp. e Streptococcus sp. (SILVA, JUNQUEIRA e SILVEIRA, 1997). Portanto, o presente trabalho demonstra que a utilização do filme strech para envelopamento aumenta a possibilidade da presença de microrganismos patogênicos nas carcaças, expondo a população consumidora a um maior risco através do consumo desses produtos cárneos.

Devido ao aumento da população desse grupo de microrganismos observado, a etapa da utilização do filme strech contida no fluxograma de produção de carne bovina deve ainda ser levada em consideração durante a avaliação de risco dentro do Programa de Análise de Perigos e Pontos Críticos de Controle (APPCC) das indústrias, o qual obrigatoriamente deve estar implantado nas indústrias supervisionadas pelo SIF (BRASIL, 1998).

Phillips et al. (2001) analisaram carcaças bovinas após refrigeração e encontraram valores médios de 2,6 $\times 10^{2} \mathrm{UFC} / \mathrm{cm}^{2}$. Hansson (2001) avaliou a contagem desse grupo em plantas frigoríficas com alta e baixa capacidade de abate, encontrando valores médios de $3,8 \times 10^{2} \mathrm{UFC} / \mathrm{cm}^{2}$ e $2,7 \times 10^{3} \mathrm{UFC} / \mathrm{cm}^{2}$ respectivamente. Os dois trabalhos encontraram valores médios inferiores aos obtidos no presente estudo. Porém, as condições observadas neste estudo são satisfatórias, visto que as contagens de mesófilos em carcaças bovinas são indicativas de más condições de higiene durante as etapas de abate dos animais quando superiores a $10^{5} \mathrm{UFC} / \mathrm{cm}^{2}$ (GIL, 2000).

Os microrganismos psicrotróficos apresentaram diferença apenas no tempo, ou seja, não houve diferença entre os tratamentos, sendo que o logaritmo de psicrotróficos no T0 foi de $2,00 \mathrm{UFC} / \mathrm{cm}^{2}$, e no T24 horas, de 2,32 UFC/ $\mathrm{cm}^{2}$. Tais valores foram inferiores ao encontrado

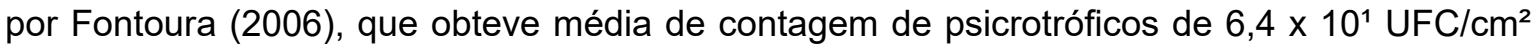

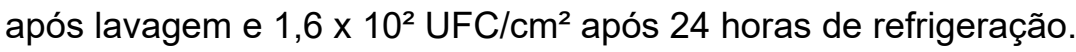

Para a presença de Listeria spp., das 50 amostras coletadas de carcaças não strechadas (T2) no T0 e no T24, apenas uma (2\%) demonstrou a presença desse gênero de microrganismo, enquanto duas (4\%) das amostras obtidas de carcaças strechadas (T1) também foram consideradas positivas. Fontoura (2006) avaliou a ocorrência de Listeria spp. em um abatedouro de bovinos no estado de São Paulo e não encontrou a presença de tal gênero de bactéria nas carcaças quentes e após o resfriamento, justificando tal achado pela boa higiene observada durante 0 abate dos animais. A frequência da presença desse microrganismo também é demonstrada por Silveira (2010), que avaliou 110 amostras do ambiente e de carcaças de um frigorífico de bovinos e encontrou 12 (10,90\%) contaminadas com Listeria spp., sendo que todas as positivas foram obtidas em etapas em que o animal apresentava-se com couro, diferentemente do presente trabalho.

Já para enterobactérias, das 50 amostras obtidas (T0 e T24) das carcaças não strechadas (T2), três (6\%) apresentaram a presença desse grupo, enquanto, no grupo das carcaças strechadas (T1), oito amostras (16\%) foram consideradas positivas. Entretanto, as contagens de enterobactérias e de Listeria spp. não apresentaram diferença estatística entre 
os tratamentos, evidenciando que a aplicação do filme strech nas carcaças não interferiu significativamente nesses parâmetros analisados neste trabalho, considerados como indicadores da presença de perigos à saúde pública (ICMSF, 1984).

\section{ABSTRACT \\ USE OF STRETCH FILM IN PHYSICAL, CHEMICAL AND MICROBIOLOGICAL PARAMETERS OF CATTLE CARCASSES}

It was aimed to evaluate the effect of using stretch film in physical-chemical and microbiological parameters of bovine carcasses. 25 carcasses were evaluated, of that 25 half-carcasses were stretched and the other 25 half-carcasses were not stretched, obtained from the same animal, after final washing and after the sanitary maturation 24 hours period at the freezing chambers. The $\mathrm{pH}$, the temperature inside the Longissimus dorsi muscle and weight on the abattoir balance were assessed in the half-carcasses. Also samples were collected obtained from swabs to plate counts to determine mesophiles and psychrotrophic viable microorganisms, enterobacteriaceae and Listeria spp. Assessing the temperature, it was observed that there was a statistical significant difference $(p<0.05)$ among the treatments after the 24 hours of sanitary maturation period. The stretched carcasses had higher temperatures $\left(1.86^{\circ} \mathrm{C}\right)$ compared to the non-stretched carcasses $\left(0.57^{\circ} \mathrm{C}\right)$. This fact positive influenced the mesophiles microorganisms growth, that differed significantly $(p<0.05)$. The mesophilic microorganisms were evaluated based on the logarithm, that was 2.62 UFC/ $\mathrm{cm}^{2}$ for non-stretched carcasses and $3.49 \mathrm{UFC} / \mathrm{cm}^{2}$ for stretched carcasses, both after 24 hours of sanitary maturation. It was observed that there was no significant difference in the other parameters. It is concluded that stretch film establishes higher temperatures on bovine carcasses after 24 hours of sanitary maturation and positively influenced the multiplication of mesophilic microorganisms.

KEYWORDS: ENTEROBACTERIACEAE, LISTERIA SPP., SANITARY MATURATION, MESOPHILES, PSYCHROTROPHIC

\section{CONCLUSÕES}

O filme strech nas carcaças interfere em alguns parâmetros avaliados, fazendo com que estas permaneçam com temperaturas mais elevadas após 24 horas de maturação sanitária e assim favoreçam a multiplicação de microrganismos mesófilos, considerados indicadores da presença de deteriorantes e patogênicos. Deve-se atentar para a utilização de tal prática durante a manutenção das carcaças nas câmaras frias e incluí-la na avaliação de risco dentro do Programa de APPCC nos abatedouros de bovinos.

\section{REFERÊNCIAS}

1 ABIEC, Associação Brasileira das Indústrias Exportadoras de Carne. Exportações brasileira de carne bovina. Jan/2013 - Dez/2013. Disponível em: <http://www.abiec.com.br/download/Relatorio\%20exportacao\%202013_jan_dez.pdf>, Acesso em 25 fev. 2014.

2 APHA.Committee on Microbiological Methods for Foods. Compendium of methods for the microbiological examination of foods.4.ed. Washington: APHA,2001, 676p. 
3 BRASIL. Ministério da Agricultura, Pecuária e Abastecimento. Secretaria de Defesa Agropecuária- DAS. Departamento de Inspeção de Produtos de Origem Animal - DIPOA. Divisão de Normas Técnicas - DNT. Decreto Lei $n^{\circ} 30691$, de 29 de março de 1952. Alterados pelos Decretos no 1255 de 25/06/62, $n^{\circ} 1236$ de 02/09/94, $n^{\circ} 1812$ de 08/02/96 e $n^{\circ}$ 2244 de 04/06/97. Regulamento da Inspeção Industrial e Sanitária de Produtos de Origem Animal - RIISPOA. Brasília: RIISPOA, 1997, 241p.

4 BRASIL, Ministério da Agricultura, Pecuária e Abastecimento. Portaria $n^{\circ} 46$, de 10 de fevereiro de 1998. Institui o Programa de Análise de Perigos e Pontos Críticos de Controle (APPCC) a ser implantado nas indústrias de produtos de origem animal. Diário Oficial da União, Seção I, 10 de fevereiro de 1998.

5 BRASIL, Ministério da Agricultura, Pecuária e Abastecimento. Quantidade de abate estadual por ano/espécie. 2013. Disponível em: <http://sigsif.agricultura.gov.br/sigsif_cons/!ap_abate_estaduais_cons?p_select=SIM>, Acesso em 25 fev. 2014.

6 EVANGELISTA, J. Tecnologia dos alimentos. 2ed, São Paulo, Ed. Atheneu, 2000, 674p.

7 FONTOURA, C. L. Estudo microbiológico em carcaças bovinas e influência da refrigeração sobre a microbiota contaminante. 2006. Dissertação (Mestrado) em Medicina Veterinária. Universidade Estadual Paulista “Julio de Mesquita Filho", Faculdade de Ciências Agrárias e Veterinárias de Jaboticabal.

8 GARCIA-LÓPEZ, M. L.; PRIETO, M.; OTERO, A. In: The physiological atributes of Gram-negative bacteria associated with spoilage of meat and meat products. DAVIES, A.; BOARD, R. The microbiology of meat and poultry. London, 1-34p, 1998.

9 GIL, J. A. S. I. Manual de inspeção sanitária de carnes. 2 ed. Lisboa: Fundação Calouste Gulbenkian.2000,485p.

10 HANSSON, I. B. Microbiological meat quality in high- and low-capacity slaughterhouses in Sweden. Journal of Food Protection, v. 64, n.6, p.820-825, 2001.

11 HUFF-LONERGAN, E.; LONERGAN, S. M. Mechanisms of water-holding capacity of meat: The role of postmortem biochemical and structural changes. Meat Science, p.194-204, 2005.

12 ICMSF, International Commission on Microbiological Specifications for Food. Microorganismos de los alimentos: técnicas de análisis microbiológico. Zaragoza:Acribia, 1984, 431p.

13 JAMES, S.The chill chain from "carcass to consumer. Meat Science, v. 43, p.203- 216, 1996.

14 LOPES, C. M. M.; OLIVEIRA, C. A. F.; Avaliação da contaminação microbiana superficial de carcaças, em diferentes etapas do abate de bovinos e suínos. Revista Higiene Alimentar, v.16, n.92/93, p.71-75,2002.

15 MATOS, A. V. R.; NUNES, L. B. S.; VIANNA, C.; SPINA, T. L. B.; ZUIM, C. V.; POSSEBON, F. S.; XAVIER, D. M.; FERRAZ, M. C.; PINTO, J. P. A. N. Listeria monocytogenes, E. coli O157, Salmonella spp. e microorganismos indicadores em carcaças bovinas para exportação. Arquivo Brasileiro de Medicina Veterinária e Zootecnia, v.65, n.4, p.981-988, 2013.

16 PARDI, M. C.; SANTOS, I. F.; SOUZA, E. R.; PARDI, H. S. Ciência, higiene e tecnologia da carne. Goiânia:CEGRAF UFG, /Niterói, : EDUFF, 2001,1145p.

17 PHILLIPS, D.; SUMNER, J.; ALEXANDER, J. F.; DUTTON, K. M.; Microbiological quality of Australian beef. Journal of Food Protection,v.64, n.5, p.692-696, 2001.

18 SAMPAIO, G. S. L. Avaliação da perda de peso, da condição higiênico-sanitária e tecnológica de meias carcaças e quartos bovinos revestidos com polietileno durante o resfriamento. 2013. Dissertação (Mestrado em Higiene Veterinária e Processamento Tecnológico de Produtos de Origem Animal) — Universidade Federal Fluminense, 2013. Disponível em: <http://www.uff.br/higiene_veterinaria/teses/m-GUILHERME\%20SICCA.pdf>, Acesso em 25 fev. 2014.

19 SAVELL, J. W.; MUELLER, S. L., BAIRD, B. E. The chilling of carcasses. Meat Science, v.70, p.449-459, 2005.

20 SILVA, N.; JUNQUEIRA, V. C. A.; SILVEIRA, N. F. A. Manual de métodos de análises microbiológicas de alimentos. São Paulo, Ed. Varela, 1997, 295p.

21 SILVEIRA, J. G. S. Investigação de Listeria sp. E microorganismos mesófilos totais em carcaças bovinas e ambiente industrial de abatedouro frigorífico. Dissertação (Mestrado em Microbiologia Agrícola e do Meio Ambiente) - Universidade Federal do Rio Grande do Sul, 2010. Disponível em: <http://www.lume.ufrgs.br/handle/10183/28738>, Acesso em 01 de mar. 2014.

22 UNITED STATES DEPARTAMENT OF AGRICULTURE (USDA). Food Safety and Inspection Service. Pathogen Reduction. Federal Register, Washington, v.61, n.144, July, 1996. 
23 VIEIRA, C.; DIAS, M.T.; MARTIINEZ, B.; GARCÍA-CACHÁN, M.D. Effect of frozen storage conditions (temperature and length of storage) on microbiological and sensory quality of rustic crossbred beef at different states of ageing. Meat Science., v. 83, p.398-404, 2009. 